\title{
Antibodies against BCG and M. tuberculosis H37Ra do not Consistently Recognize Pathogenic M. tuberculosis whole Cells but Recognize their Cytoplasmic Constituents. Implications for the Variability and Protective Efficacy of the Vaccine
}

\author{
Melanie Rennou ${ }^{1}$, Marie C Maes ${ }^{1}$, HH Maes ${ }^{1}$, Roland F Maes ${ }^{1 *}$, Z Kidwai $^{2}$, H Tasbiti ${ }^{3}$ and A Bahrmand ${ }^{3}$ \\ ${ }^{1}$ Anda Biologicals, Strasbourg, France \\ ${ }^{2}$ Ehsanullah's Laboratory, Karachi, Pakistan \\ ${ }^{3}$ Pasteur Institute of Iran, Tehran, Iran
}

*Corresponding author: Roland F Maes, Anda Biologicals, Strasbourg, France, Tel: 0033388501948; E-mail: anda.mars@wanadoo.fr

Received date: March 30, 2016; Accepted date: April 19, 2016; Published date: April 26, 2016

Copyright: ( 2016 Rennou M, et al. This is an open-access article distributed under the terms of the Creative Commons Attribution License, which permits unrestricted use, distribution, and reproduction in any medium, provided the original author and source are credited.

\begin{abstract}
The production of antibodies by mycobacterial pathogens and BCG vaccine is still poorly understood. This study showed that antibodies raised against cells of TB strain H37Ra and against whole sonicates of BCG do not react consistently with whole cells of TB pathogenic strains and very poorly with whole BCG cells. These antibodies react with the internal components of the BCG cell, i.e. A60 and cytoplasmic constituents. It is concluded that the failure of antibodies raised against BCG to recognize some pathogenic strains permits the unrestricted entrance of these pathogenic bacteria in a vaccinated host and may explain the variable efficacy of this vaccine. The reactivity of these antibodies with internal components of the mycobacteria may impede the progress of the infection toward disease. These protective antibodies are not consistently produced in BCG vaccinees and may explain the excess TB and leprosy cases sometimes observed after vaccination.
\end{abstract}

Keywords: BCG; TB; Leprosy; Vaccine; Antibodies

\section{Introduction}

We develop a flow-through method for the detection of the tuberculosis pathogen to provide a sensitive and affordable detection method in regions where the prevalence of tuberculosis is high. It is based on the labeling of the bacilli with antibodies raised against the cells of a-virulent TB strain H37Ra. The method was tested in the field and gave equivocal results with sputum samples shown positive by AFB staining. The causative agent was found to be the specificity of the primary rabbit antibodies used to label the bacilli. This observation led to wider conclusions on the activity of BCG used as a vaccine.

The efficacy and innocuity of BCG have been disputed since 1927 [1] and its general failure is now accepted [2], with the reservation that the vaccine is not consistently inactive but varies in efficacy according to geographic location and disease characteristics [3]. The variable efficacy has remained without explanation until today [4]. The adverse side effects were credited to immuno-compromission of the host [5] unable to defend itself against the attenuated BCG vaccine. Our data, based on an analysis of humoral antibodies elicited by various mycobacterial antigens, shows that the phenotypic variation of the outer membrane of the pathogen is likely to be the culprit for the variable efficacy of the vaccine, but more than immune-compromising of the host is at play in the excess cases of mycobacterial infections sometimes encountered in vaccinees.

\section{Materials and Methods}

The steps of the flow-through method are: a liquid sample is filtered on a $0.45 \mu \mathrm{m}$ nitrocellulose membrane (Advanced Microdevices, Ambala, Cannt, India). The bacteria present ion the sample is retained at the surface of the membrane and is labeled with rabbit antibodies against whole mycobacterial cells. The presence of rabbit gammaglobulins is visualized on the membrane with gold-labeled protein A.

The main difficulty encountered in the development is the solubilisation of sputum.

\section{Bacilli filtered on the retaining membrane were:}

- Freeze-dried inactivated bacilli of M. tuberculosis strain H37Ra, from Difco (France).

- Pathogenic bacilli in the fresh sputum of TB positive patients from Tehran.

- Pathogenic bacilli isolated by centrifugation from the sputum of patients diagnosed in Paris.

- Live biomass of BCG bacilli, obtained from the Institut Pasteur du Brabant (PIB).

- Freeze-dried live BCG bacilli from Aventis-Pasteur Monovax lot W5586-2.

- Live cultured pathogenic bacilli from the sputum of patients diagnosed in Tehran.

Other patient material originated from:

- Fresh sputa of non-TB patients (courtesy Dr. Fraisse, CHU Hautepierre, France). One of these samples was determined by our method to be positive, after reception. 
Citation: Rennou M, Maes MC, Maes HH, Maes RF, Kidwai Z, et al. (2016) Antibodies against BCG and M. tuberculosis H37Ra do not Consistently Recognize Pathogenic M. tuberculosis whole Cells but Recognize their Cytoplasmic Constituents. Implications for the Variability and Protective Efficacy of the Vaccine. Clin Microbiol 5: 246. doi:10.4172/2327-5073.1000246

Page 2 of 6

- Frozen sputa of non-TB patients (courtesy of Dr. D. Banerjee, Saint George Hospital Medical School, London). Frozen sputa of non-TB and TB Brazilian patients, courtesy of Dr. M. Perkins (WHO, Geneva, Switzerland).

- Fresh sputa, positive and negative, were analyzed on site at the Pasteur Institute of Iran, at the laboratory of Dr. Ehsanullah, Karachi and by Dr. S. Gokhale and M. Singh at the Command hospital, Lucknow.

- Samples from diverse biological fluids were analyzed on site by Dr. Gokhale at the Command Hospital, Lucknow.

- CRF fluids were analyzed on site by Pr. Chandramucki at the NIMHANS in Bangalore.

Non-TB patients' sputa were used for spiking purposes and determination of back-ground adsorption. Homogenized cell suspensions of cultures and other biomasses were obtained by suspending the material in isotonic saline and vigorous shaking. The concentration of bacilli was evaluated by the classical AFB stain.

The number of bacterial cells used for the determination of the specificity of antibodies in the test was, for strain H37Ra, adjusted to 1 bacillus per microscopic field, corresponding to $2.3 \times 10^{6}$ bacteria $/ \mathrm{ml}$. Fifty microliters of this aqueous suspension, i.e. $1.15 \times 10^{5}$ bacteria, was passed through the retaining membrane. For the evaluation of the specificity of the antibodies against the two BCG strains, the concentration of the bacilli was increased to 50 bacilli per microscopic field, corresponding to $1.15 \times 10^{8}$ bacilli $/ \mathrm{ml}$. Fifty microliters of the bacterial suspension, i.e. $5.7 \times 10^{6}$ bacteria, were passed through the retaining membrane. For cultured pathogenic strains of $\mathrm{TB}$, the concentration was adjusted to 1 MacFarland turbidity $\left(3 \times 10^{8}\right.$ cells $/ \mathrm{ml}$ ) and $50 \mu \mathrm{l}$, corresponding to $1.5 \times 10^{7}$ bacilli, were used in the test. All of the above were used either as is, or else spiked in TB-free sputa. For the pathogenic bacilli in sputa, samples were used that contained more than 10 bacteria per microscopic field, as determined by AFB staining. Fifty microliters of sputum, i.e. more than $1.15 \times 10^{6}$ bacteria were dissolved in $\mathrm{N}$-acetyl-cysteine/ $\mathrm{NaOH}$ and passed through the retaining membrane. As control, TB strain H37Ra at a concentration of 1-2 bacilli per microscopic field was spiked in TBnegative sputa and processed in the same manner.

The sensitization of the membrane with mycobacterial antigens was done by spotting 5 micrograms of proteins on the membrane and drying. The antigens used to sensitize the membrane were:

- Antigen 60 (A60) from M. bovis, strain BCG obtained from PIB.

- Cytoplasm from M. bovis, strain BCG obtained from PIB.

- Cytoplasm from heat-inactivated wild TB strain.

These antigens were obtained by cell disruption and, in the case of the A60 complex, chromatographic isolation by standard methods [6]. Heat-inactivation of bacteria was achieved by incubating the suspension of cells during 60 minutes at $80^{\circ} \mathrm{C}$. No positive cultures were obtained from the inactivated bacilli. The inactivated bacteria appeared whole under the microscope.

- Antibodies used to label the cells and the antigens retained on the membrane were:

- Rabbit antibodies against inactivated freeze-dried M. tuberculosis strain H37Ra (Difco 231141), (Neosystem, France).

- Rabbit antibodies against a whole sonicate of the Copenhagen strain of BCG (Dako, Denmark).

- Rabbit antibodies against A60 of BCG (Neosystem, France).
- Rabbit antibodies against whole heat-inactivated pathogenic bacilli obtained from the Pasteur Institute of Iran (Neosystem, France).

Immunizing solutions for the production of antibodies by Neosystem were provided by the authors and consisted of $3.75 \times 10^{8}$ heat-inactivated pathogenic TB cells in $500 \mu \mathrm{l}$ of physiological solution and of $450 \mu \mathrm{g} M$. tuberculosis H37Ra inactivated freeze-dried cells in $500 \mu \mathrm{l}$ physiological solution. Both vaccines were homogenized with an equal amount of Freund's incomplete adjuvant and inoculated monthly.

The antisera were precipitated with ammonium sulfate, dissolved in a tenth volume phosphate-buffered saline, dialyzed and clarified by low speed centrifugation. The working dilution of the primary rabbit antibodies was evaluated by the reactivity of different concentrations of these antibodies with whole cells of $M$. tuberculosis H37Ra spotted on the membrane. The rabbit antibodies suitably diluted in an isotonic medium containing $1 \%$ bovine albumin and $0.1 \%$ tween 20 at $\mathrm{pH} 7.2$ were contacted $(80 \mu \mathrm{l})$ with the sensitized membrane and the antibodies attached to the sensitizing antigens were revealed with $80 \mu \mathrm{l}$ of a suitably diluted Protein A- Gold (40 nanometers) solution purchased from British Biocell (UK). The intensity of the red coloration, indicative of the presence of rabbit gamma-globulins on the membrane, was visually estimated with a gradation extending from -, i.e. absence of coloration, to ++++ , indicative of intense coloration. The limit of sensitivity was signaled by "+/-".

Were evaluated the interaction of antibodies with bacilli of tuberculosis strain H37Ra, cultured pathogenic TB bacilli originating from the Pasteur Institute of Iran, live BCG from Aventis, cytoplasm and A60 of BCG. The results obtained with the other pathogenic bacilli were restricted to their interaction with antibodies against strain $\mathrm{H} 37 \mathrm{Ra}$ and were used essentially to verify the phenotypic variation of pathogenic strains. These antigens were not anymore available for additional studies with other antibodies.

\section{Results}

Rabbits produced abundantly antibodies against whole bacilli of the M. tuberculosis H37Ra strain and allowed the set-up of the flowthrough test wherewith three antibodies and various antigens were tested. A number of sputa collected from TB patients living in different parts of the world were analyzed. The size of the samples was not in our power to define. The results of this analysis are given in Table 1.

No difference in response was seen, whether the sputa were used fresh or thawed. Antibodies raised against bacilli of strain H37Ra failed to recognize pathogenic strains in biologic samples in Bangalore, observed by Pr. Chandramucki who found no response when analyzing CSF samples from tuberculous meningitis patients. The absence of recognition of pathogenic strains and BCG by anti-whole cell H37Ra and their poor recognition by anti-sonicate BCG antibodies was confirmed by the analysis of 9 culture-isolated strains obtained from the Pasteur Institute of Iran, grown on Löwenstein medium and suspended in buffered physiological saline at one Mac Farland turbidity. No immunological reaction was observed with antibodies against $\mathrm{H} 37 \mathrm{Ra}$ and only 3 samples were poorly recognized (score $-/+$ ) with anti-BCG. The two BCG's were concentrated in saline to 50 bacteria per microscopic field for the evaluation of their immunological reactivity.

These results were at odds with previous observations of positivity of a smear-positive sputum sample obtained in Strasbourg, of 12 
Citation: Rennou M, Maes MC, Maes HH, Maes RF, Kidwai Z, et al. (2016) Antibodies against BCG and M. tuberculosis H37Ra do not Consistently Recognize Pathogenic M. tuberculosis whole Cells but Recognize their Cytoplasmic Constituents. Implications for the Variability and Protective Efficacy of the Vaccine. Clin Microbiol 5: 246. doi:10.4172/2327-5073.1000246

Page 3 of 6

smear-positive sputa from Brazilian TB patients, and also in diverse samples analyzed in Lucknow. Interestingly, a fairly good response was obtained there in extra-pulmonary TB specimens but equivocal results with sputum, in that the positivity of sputa asserted by microscopic examination was sometimes but not always confirmed by the flowthrough method.

\begin{tabular}{|c|c|c|c|c|}
\hline \multicolumn{2}{|r|}{ Samples } & \multicolumn{3}{|c|}{ Antibodies against } \\
\hline & & H37Ra & A60 & BCG \\
\hline \multirow{9}{*}{ TB } & H37Ra $1.15 \times 10^{5}$ bact. & ++++ & +++ & ++++ \\
\hline & France 1 pat. & +++ & * & \\
\hline & Brazil 12 pat. & ++ to ++++ & & \\
\hline & India extra pulm 30 pat. & + to ++++ & & \\
\hline & India 50 pat. & - to +++ & & \\
\hline & Iran 50 pat. & - & & \\
\hline & Iran\# $1.5 \times 10^{7}$ bact. 9 pat. & - & & \\
\hline & France\#\# 12 pat. & - & & \\
\hline & Pakistan 5 pat. & - & & \\
\hline \multirow{4}{*}{ BCG } & PIB $5.7 \times 10^{6}$ bact. & $+/-$ & $+/-$ & $+/-$ \\
\hline & Aventis $5.7 \times 10^{6}$ bact. & $+/-$ & $+/-$ & $+/-$ \\
\hline & A 605 micrograms & ++++ & ++++ & ++++ \\
\hline & Cytoplasm 5 micrograms & ++++ & +++ & ++++ \\
\hline
\end{tabular}

*not done; \#cultured samples, analyzed at a concentration of 1 McFarland in buffer; \#\#concentrated sediment suspended in buffer after decontamination.

Table 1: Results of flow-through tests on positive samples from various origins using 3 different detection antibodies.

We assessed the immunological reactivity of antibodies raised in rabbits against a heat-inactivated strain of pathogenic bacilli. The antibody recognized A60 (score: ++++ ) as well as whole cells of $\mathrm{TB}$ strain H37Ra (score: ++++ ), less efficiently the cells of its own immunizing strain (score: ++ ), and scarcely BCG (Aventis) (+/-). It recognized very efficiently (score: ++++ ) the cytoplasm of the lysed cells of the wild strain used for immunization. After centrifugation during 30 minutes at $16,000 \mathrm{rpm}$, the immunological activity of the lysed cells remained confined to the supernatant $(++++)$ with little immunological reactivity observable with the re-suspended sediment, containing the cells debris and cell membranes.

The immunological specificity of the cell membranes of the different mycobacterial entities here analyzed could also be a property of the A60 and the cytoplasm. This was suggested by the slightly reduced reactivity of antibodies against A60 extracted from BCG with H37Ra cells (Table 1). The large amount of A60 used as capture antigen $(5 \mu \mathrm{g})$ had been applied to unequivocally establish the interaction of the antibodies with it but could have been too great to assess any difference in specificity of the different antibodies analyzed. To investigate this possibility, the cytoplasm of a wild Iranian strain of TB, used to raise antibodies, and the cytoplasm of BCG (PIB) were spotted on a membrane and the reactivity of antibodies against the wild strain, against H37Ra and against A60 from BCG (PIB) were evaluated in a flow-through system. The results are given in Table 2.
The intensity of the coloration obtained with antiserum against A60 of BCG was significantly lower (score between + and ++ ) and significantly higher (score between ++ and +++ ) than those obtained with the antibodies raised against TB strains, yet were not due to a difference in concentration of antibodies applied. The observed differences indicated a difference in specificity.

\begin{tabular}{|l|l|l|}
\hline Antiserum against & Cytoplasm wild strain & Cytoplasm BCG \\
\hline Wild strain (Iran) & ++++ & $+/-$ \\
\hline H37Ra & +++ & $+/-$ \\
\hline A60 (BCG) & $++/-$ & +++- \\
\hline
\end{tabular}

Table 2: Reactivity of 3 different antibodies with the cytoplasm of a wild pathogenic TB strain and the cytoplasm of BCG.

\section{Discussion}

The lack of sensitivity of the test is not due to an inactivation of one of its components, since we obtained good sensitivity with positive samples in some cases. The problem was traced to the primary rabbit antibodies used, that do not consistently recognize pathogenic strains. Important issues uncovered by this study are the antigenic variation of the cell surface of wild tuberculosis strains, the failure of antibodies to BCG to recognize whole BCG cells as efficaciously as their cytoplasmic constituents, the protective activity of the BCG vaccine and the study of the humoral response elicited by TB invasion and BCG vaccination. These issues are developed hereunder.

\section{Antibody production against mycobacterial antigens}

The table reveals that the anti- $M$. tuberculosis H37Ra antibodies recognize very well bacilli of strain $M$. tuberculosis $\mathrm{H} 37 \mathrm{Ra}$, very poorly BCG bacilli, not at all the pathogenic $M$. tuberculosis strains originating from some cities, with equivocal results in Lucknow and good results elsewhere. Recognition of the inner components (cytoplasm and A60) of the BCG cell is noted.

BCG induced a higher level of anti-BCG antibodies in mice when the bacilli were grown in asparagine-containing medium, versus starch- and peptone-containing medium [7]. This effect of growth medium on immunogenicity cannot explain our own observations, since the failure of recognition was observed when TB-positive sputa were directly analyzed, when bacilli were isolated by centrifugation from sputum and re-suspended in saline and when bacilli cultured on Löwenstein medium were washed and suspended in isotonic saline, but was not observed when TB strain H37Ra was analyzed, either suspended in sputum or in saline. The condition of the cells, namely fresh, frozen or freeze-dried was not at cause either, because freezedried H37Ra cells were recognized by all 4 antibodies, freeze-dried BCG was not and neither were many positive fresh and frozen sputum samples.

As with antibodies directed against whole H37Ra cells, antibodies against $\mathrm{A} 60$ of BCG and against whole sonicates of BCG recognized poorly whole BCG cells (PIB and Aventis) and did not recognize cells of pathogenic strains (Iran and France) under the experimental conditions applied. By contrast, they recognized the cytoplasmic constituents of BCG (A60 and cytoplasm) and also H37Ra cells, which is puzzling. Antigen 60 was itself recognized by all four antibodies used in this study. One concludes that this antigen would be accessible late 
during an infection [8], when host cells lyse. This observation confirms that A60 is mainly intracellularly located [9]. Yet, anti-A60 antibodies recognize whole cells of a-virulent tuberculosis strain H37Ra. The paradox is elucidated by assuming that the a-virulent tuberculosis strain H37Ra presents on its surface much more of the constituents of A60, which is a complex bearing at least 30 antigenic constituents presenting about 85 particular epitopes. This is contrary to all other strains tested here, where the presence of A60 constituents on the surface would be too low to be evidenced by our method of detection. The BCG cells bear more epitopes corresponding to A60 on its surface than do wild TB strains because A60 antibodies extracted from BCG recognize the cell surface of BCG cells and, in addition, their specificity is optimal. Noteworthy is that the stained cells of strain H37Ra appeared under the microscope as slightly bent rods, which set it completely apart from all other strains here, analyzed, be they pathogenic or attenuated, which appeared coccoidal. Noteworthy is the difference observed in the reactivity of the different antibodies with the cytoplasm. There remains no doubt that the antigens 60 originating from different mycobacterial species are immunologically distinct. This aspect of the humoral immunity of mycobacteria will be studied in more detail in the following communication.

It is possible to recognize a geographical pattern of sensitivity? Samples from Brazil are detected by anti-H37 RA antibodies while those from Karachi and Tehran are not detected by any of the applied antibodies. Both types seem to occur in India and France. The evidence is still scant but is an attractive hypothesis because it provides a simple explanation for the variable efficacy of the vaccine. We assume that the reasons for this variation are multiple and hard to pinpoint at this stage. One may advance the premature abandon of treatment by patients, which favors the growth of resistant strains that may present alterations of their cell surface. These alterations may vary according to the regimen applied [10]. Another source of variation that could be operative among the Hindu population of India is the consumption of raw milk from infected cows.

Heat-inactivated pathogenic tuberculosis cells elicit the formation of antibodies against their cell surface. This production is not massive (score ++ ), compared to the response observed simultaneously against their soluble cytoplasm (score ++++ ). The reactivity of these antibodies with A60 of BCG is low compared to that of antibodies raised against A60 of BCG. We suppose that the destruction of the cells by the host during the vaccination process was responsible for the antibodies produced against intracellular constituents, which explains why H37Ra cells were also detected. A weak humoral response against BCG cells was observed with this fourth antibody, whose intensity $(+/-)$ was similar to the one observed with the three other antibodies.

We do not negate the impact of virulence factors on the infectiousness of various mycobacterial species and strains. We cannot, however, ignore the compelling evidence of the powerful humoral immune response $M$. tuberculosis strain H37Ra elicits against its own cell surface and cytoplasmic constituents and attribute a considerable part of the avirulence of this strain to this dual response. This basic observation allows an explanation for the variable efficacy of BCG.

\section{The antibodies produced by BCG}

The failure of rabbit antibodies to protect rabbits passively against an aerobic TB challenge [11], the direct relation between delayed hypersensitivity and the resistance to infection in BCG vaccinated mice [12], and the partial to total failure of recognition of BCG cells and TB pathogenic strains by rabbit antibodies against BCG sonicates, which our study confirms, has led to the generally accepted conclusion that antibodies play no role or only an insignificant role in the host's immune defense against mycobacterial infections [13-15]. Our results indicate that, on the contrary, it may play an essential role.

An experimental approach to the study of this role is limited by the life span and the susceptibility to infection of animal models and the inordinate use of massive amounts of non-viable antigens potentiated by adjuvants (in our case, Freund incomplete adjuvant) to raise antibodies. Under these experimental conditions all vaccinated rabbits in this study produced antibodies against the cytoplasmic constituents of BCG. The reproach one could make against our experimental design is the use of BCG sonicates instead of whole BCG cells, in that whole cells may produce more readily antibodies against whole BCG cells. However, three observations we made support the idea that BCG fails to produce antibodies against the cell surface of most pathogenic TB strains. The first observation is that $\mathrm{H} 37 \mathrm{Ra}$ antibodies were obtained with whole cells and these cells were found wanting in their ability to elicit antibodies against whole pathogenic cells from Iran and against whole BCG cells (PIB) (Table 1). The second is that the antibody response elicited against H37Ra cells fits almost perfectly with the response obtained with BCG sonicates. The third is that antibodies against pathogenic cells (Iran) do not recognize BCG cells (Aventis: score $+/-$ ) with the same efficacy than wild strains (score ++ ).

Further to that, studies in humans [16-19] show firstly that BCG does not induce IgG antibodies against $\mathrm{A} 60$ in some vaccinees, and secondly that some TB patients seeking a specific treatment fail to produce IgG antibodies against A60 [20].

Rota monitored the production of antibodies against A60 and PPD by BCG-vaccinated two months-old infants in Ankara during three years. Her results [16] are that the BCG given to human newborns was found effective in the formation of antibodies of the IgG class against A 60 , although only in less than $50 \%$ of the vaccinated population $[2,8,17]$. The conclusion is that BCG would likely not prevent the entry of TB in most vaccinees because the antibodies raised against BCG do not recognize whole cells of most pathogenic strains and, in newborns raised in Ankara, would prevent the progression of a TB infection toward disease in less than half of the vaccinees because the BCG failed to induce the synthesis of IgG antibodies against the internal components of the bacilli in the other half. Ours and other animal studies $[6,18,19]$ show however that $\mathrm{A} 60$ is per se an excellent immunogen, which induces production of anti-A60 IgG's in all cases, recognizing the A60 of other mycobacterial species, albeit with less efficacy.

We establish a link between protection against progression toward disease and production of IgG antibodies against cytoplasmic constituents. This correlation is based on the absence or much reduced presence of IgG antibodies against A60 in some patients seeking specific treatment, with the subsequent rise of anti-A60 antibodies in successfully treated patients $[20,21]$. The production of antibodies by these patients correlates with the disappearance of positive cultures $[20,22]$. We have two possible explanations for this delayed rise of antiA60 antibodies: firstly, the cytoplasm of bacteria killed by the treatment becomes exposed to the immune system, which would be enough to explain the rise. A second possibility, which we favor, is that live bacteria are immunosuppressive [23]; it is their inactivation that allows the synthesis of the A60-antibodies.

The immunosuppression by live mycobacteria of antibodies' production against mycobacterial cytoplasmic constituents is an 
Citation: Rennou M, Maes MC, Maes HH, Maes RF, Kidwai Z, et al. (2016) Antibodies against BCG and M. tuberculosis H37Ra do not Consistently Recognize Pathogenic M. tuberculosis whole Cells but Recognize their Cytoplasmic Constituents. Implications for the Variability and Protective Efficacy of the Vaccine. Clin Microbiol 5: 246. doi:10.4172/2327-5073.1000246

Page 5 of 6

attractive concept because it sheds light on the infection process by TB and BCG.

\section{The potentiation of mycobacterial infections by the BCG}

The failure of rabbit antibodies to protect rabbits passively against an aerobic TB challenge [11] is traced by us in part to the absence of antibodies against the cell surface antigens of the challenging bacilli. We think that an additional factor plays a considerable role: the enhancing effect of antisera on infections was reported two years later in mice [24] and this paradox was verified again in 1991 [25]. Both $M$. leprae and BCG are known to induce the activity of suppressor cells $[26,27]$. These act by releasing soluble suppressors of IL-2 [27] in the blood [28]. Il-2 promotes the synthesis of IgG gamma-globulins. Partial to total immunosuppression by BCG leading to cancellation of the immunological recognition by the host of cytoplasmic constituents of the challenging pathogen is discernable in humans [16]. This would potentiate mycobacterial infections in vaccinated subjects. An analysis of the combined results of several studies in humans gives us some clues. The already mentioned enhanced production of IgG antibodies against A60 in successfully treated tuberculosis patients is indicative of an immunosuppression of humoral antibodies induced by live mycobacteria against cytoplasmic constituents. The failure of about $50 \%$ of infants, vaccinated at birth in Ankara, to produce IgG antibodies against A60 may be caused by BCG immunosuppression of the humoral system. Note that in Rota's study, about $80 \%$ of vaccinated infants had DTH positivity.

The results of vaccination campaigns and sensitins' reactivity studies in vaccinated humans support the claim that BCG, on some occasions favors the proliferation of $\mathrm{TB}$ and other mycobacterial species. Tuberculosis cases among vaccinees were reported during the vaccination campaign initiated in Djibouti and Madagascar in the 1950s [2]. As early as 1960, the promotion of mycobacterial infections by BCG, including tuberculosis and leprosy, in some populations of humans and animals, was published [29-32]. Vaccinated Swedish children monitored with three different sensitins showed a 16 -fold increase of reactivity against tuberculin versus controls, from $3 \%$ to $49 \%$. This considerable increase was attributed by the authors [33] to BCG but could just as well be non-apparent infections due to TB [8]. We defend this view firstly because it has been established that the reactivity to tuberculin in Italian vaccinated subjects is not due to BCG reaction $(<5 \%)$ but to a $M$. tuberculosis infection [34], secondly because neonatal BCG vaccination had no marked impact on tuberculin skin test reactivity in Ugandan children exposed to infectious cases [35] and thirdly because there was a simultaneous 2 and 3 fold excess cases among the vaccinated Swedish children, of asymptomatic $M$. scrofulaceum (from $32 \%$ to $58 \%$ ) and $M$. avium (from $25 \%$ to $67 \%$ ). In healthy Swedish infants, the asymptomatic TB infections were confounded with BCG [33]. Unfortunately, the consequences of a vaccination are not always so benign and symptomatic cases may flare up. An excess of about $170 \%$ pulmonary tuberculosis symptomatic cases, restricted mainly to adults, was observed in South-India during the first five years that followed BCG vaccination [3,36]. A 9 fold excess of leprosy cases was observed in New Guinea, a TB-free zone, during the first five years following BCG vaccination and affected only vaccines less than 5 years old [37]. The vaccination of a South American Indian population, which was not TB naive since that disease was present on the continent before the arrival of the Europeans, but that was exposed to new pathogenic strains by contact with Europeans, had devastating consequences [38]. BCGvaccinated Gambian patients with proven pulmonary tuberculosis were significantly younger than those not vaccinated and were less likely to have nutritional oedema. None of the BCG-vaccinated TB patients died whereas $17.5 \%$ of the non-vaccinated TB patients died. Survival was attributed to the vaccination [39]. This is not disputed: the evidence is that the BCG induced a TB infection at an earlier age in immunologically better protected subjects, which allowed their recovery, whereas starving non-vaccinated elderly subjects had lost adequate immune defenses and succumbed. In Tehran, $27 \%$ of 30 vaccinated children and $30 \%$ of 70 non-vaccinated children died from tuberculous meningitis. The observed difference in mortality is not significant but speaks in favor of the vaccine. The vaccine was of some benefit since the CNS complications were much lower in the vaccinated compared with the non -vaccinated surviving patients [40]. The evidence is that the protective activity of BCG is due to a generally benign primo-infection that potentiates infections with $\mathrm{TB}$ and other mycobacterial species leading in some distinct populations, exposed to a defined mycobacterial entity, to symptoms, during the first years following vaccination.

\section{Conclusion}

The immunization with a sonicate of BCG (Copenhagen) induces antibodies that recognize very well cytoplasmic components of BCG, one standard strain of $M$. tuberculosis $(\mathrm{H} 37 \mathrm{Ra})$ and a few wild strains but whole BCG cells strains Aventis and PIB are not so well recognized. In addition, the A60 of BCG elicits antibodies that are not totally specific for the homologous components of pathogenic bacilli.

Our data supports the hypothesis that BCG vaccination does not effectively protect against tuberculosis because it induces the production of antibodies preferably against antigens that are only exposed when cells are lysed and thus when the infection is well established. We therewith provide a simple explanation why BCG does not protect against infection but prevents dissemination from the primary foci to other parts of the body [41]. The absence of creation of antibodies against the outer cell membrane of wild strains also explains the long persistence of the pathogen in the invaded host. The data further indicates that geographical variations in exposed antigens among $M$. tuberculosis strains may be the cause of the discrepant results found when BCG efficacy is analyzed in different parts of the world.

To elucidate why BCG vaccination sometimes leads to disaster, one has to take into consideration two additional factors. First, the phenotypic variation of some BCG strains may impeach effective immunological recognition of some pathogenic TB strains. This will be analyzed in the following publication. The second factor is the partial to total induction of humoral immune anergy that suppresses the formation of protective IgG antibodies against the internal constituents of the bacilli and thereby promotes mycobacterial infections by the vaccine. Pathogenic TB bacilli very probably possess a similar factor of virulence.

\section{Acknowledgments}

We thank Dr. Fraisse (Hôpital Hautepierre, Strasbourg, France) for the supply of patients' sputa. Dr. Banerjee (Saint George Hospital Medical School, London) supported our research by the generous gift of non-TB patients' sputa. Dr. S. Gokhale and M. Singh (Command Hospital, Lucknow) and Pr. Chandramucki (National Institute of Mental Health, Bangalore) have taken an active part and shown interest in this work. 
Citation: Rennou M, Maes MC, Maes HH, Maes RF, Kidwai Z, et al. (2016) Antibodies against BCG and M. tuberculosis H37Ra do not Consistently Recognize Pathogenic M. tuberculosis whole Cells but Recognize their Cytoplasmic Constituents. Implications for the Variability and Protective Efficacy of the Vaccine. Clin Microbiol 5: 246. doi:10.4172/2327-5073.1000246

Page 6 of 6

\section{References}

1. Lignières J (1927) Contribution à l'étude des qualités pathogènes du vaccin BCG contre la tuberculose. Bull Acad Méd 127.

2. Maes RF (1999) Tuberculosis II: the failure of the BCG vaccine. Med Hypotheses 53: 32-39.

3. Smith PG (1994) BCG vaccination. In: Davies PO (ed.) Clinical Tuberculosis, Chapman and Hall medical, UK.

4. Fine PE (1998) Vaccines, genes and trials. Novartis Found Symp 217: 57-69.

5. Romanus V, Fasth A, Tordai P, Wiholm BE (1993) Adverse reactions in healthy and immunocompromised children under six years of age vaccinated with the Danish BCG vaccine, strain Copenhagen 1331: implications for the vaccination policy in Sweden. Acta Paediatr 82: 1043-1052.

6. Cocito C, Vanlinden F (1986) Preparation and properties of antigen 60 from Mycobacterium bovis BCG. Clin Exp Immunol 66: 262-272.

7. Petricevich VL, Ueda C, Alves RC, da Silva MA, Moreno C, et al. (2001) A single strain of M. bovis bacillus Calmette-Guerin (BCG) grown in two different media evokes distinct immune responses in mice. Braz J Med Biol Res 34: 81-92.

8. Maes HH, Causse JE, Maes RF (1999) Tuberculosis I: a conceptual frame for the immunopathology of the disease. Med Hypotheses 52: 583-593.

9. Cocito CG (1991) Properties of the mycobacterial antigen complex A60 and its applications to the diagnosis and prognosis of tuberculosis. Chest 100: $1687-1693$

10. Khoo KH, Tang JB, Chatterjee D (2001) Variation in mannose-capped terminal arabinan motifs of lipoarabinomannans from clinical isolates of Mycobacterium tuberculosis and Mycobacterium avium complex. J Biol Chem 276: 3863-3871.

11. Reggiardo Z, Middlebrook G (1974) Failure of passive serum transfer of immunity against aerogenic tuberculosis in rabbits. Proc Soc Exp Biol Med 145: 173-175.

12. Collins FM, Mackaness GB (1970) The relationship of delayed hypersensitivity to acquired antituberculous immunity. I. Tuberculin sensitivity and resistance to reinfection in BCG-vaccinated mice. Cell Immunol 1: 253-265.

13. Konietzko N, Loddenkemper R (1999) Tuberkulose. Thieme, Germany.

14. Hopewell $\mathrm{Ph}$, Bloom B (2000) Tuberculosis and other Mycobacterial Diseases, in Textbook of Respiratory Medicine. Murray-Nadel (ed.), Springer, USA.

15. Reichman L, Hershfield E (2000) Tuberculosis, A comprehensive international approach. Marcel Dekker, USA.

16. Rota S, Beyazova U, Karsligil T, Cevheroğlu C (1994) Humoral immune response against antigen 60 in BCG-vaccinated infants. Eur J Epidemiol 10: 713-718.

17. Maes RF (1999) The tuberculosis enigma: need for a new paradigm; Importance of a knowledge of the immune status of the patients. Biomedecine 19: 1-14.

18. Coetsier C, Baelden MC, Coene M, Cocito C (1994) Immunologica analysis of the components of the antigen complex A60 of Mycobacterium bovis BCG. Clin Diagn Lab Immunol 1: 139-144.

19. Maes H, Taper H (1996) Use of sodium ascorbate and poly I:C in conjunction with a mycobacterial antigen complex as cancer preventive immunotherapy. J Exp Clin Cancer Res 1: 197-205.

20. Fadda G, Grillo R, Ginesu F, Santoru L, Zanetti S, et al. (1992) Serodiagnosis and follow up of patients with pulmonary tuberculosis by enzyme-linked immunosorbent assay. Eur J Epidemiol 8: 81-87.

21. Luh KT, Yu CJ, Yang PC, Lee LN (1996) Tuberculosis antigen A60 serodiagnosis in tuberculous infection: application in extrapulmonary and smear-negative pulmonary tuberculosis. Respirology 1: 145-151.
22. Kaustová J (1996) Serological IgG, IgM and IgA diagnosis and prognosis of mycobacterial diseases in routine practice. Eur J Med Res 1: 393-403.

23. Maes HH, Causse JE, Maes RF (1996) Mycobacterial infections: are the observed enigmas and paradoxes explained by immunosuppression and immunodeficiency? Med Hypotheses 46: 163-171.

24. Forget A, Benoit JC, Turcotte R, Gusew-Chartrand N (1976) Enhancement activity of anti-mycobacterial sera in experimental Mycobacterium bovis (BCG) infection in mice. Infect Immun 13: 1301-1306.

25. Ferreira P, Soares R, Arala-Chaves M (1991) Susceptibility to infection with Mycobacterium avium is paradoxically correlated with increased synthesis of specific anti-bacterial antibodies. Int Immunol 3: 445-452.

26. Mehra V, Mason LH, Fields JP, Bloom BR (1979) Lepromin-induced suppressor cells in patients with leprosy. J Immunol 123: 1813-1817.

27. Mustafa AS (1995) Mycobacterium bovis BCG-induced Th1 type CD4+ suppressor T cells act by suppressing IL-2 production and IL-2 receptor expression. Nutrition 11: 692-694.

28. Schauf V, Rom WN, Smith KA, Sampaio EP, Meyn PA, et al. (1993) Cytokine gene activation and modified responsiveness to interleukin-2 in the blood of tuberculosis patients. J Infect Dis 168: 1056-1059.

29. Wade HW (1960) BCG-induced activations. Int J Leprosy 28: 179-181

30. Muliyil J, Nelson KE, Diamond EL (1991) Effect of BCG on the risk of leprosy in an endemic area: a case control study. Int J Lepr Other Mycobact Dis 59: 229-236.

31. Thuc NV, Abel L, Lap VD, Oberti J, Lagrange PH (1994) Protective effect of BCG against leprosy and its subtypes: a case-control study in southern Vietnam. Int J Lepr Other Mycobact Dis 62: 532-538.

32. Griffin JF, Buchan GS (1993) Vaccination against tuberculosis: is BCG more sinned against than sinner? Immunol Cell Biol 71 : 431-442.

33. Larsson LO, Magnusson M, Skoogh BE, Lind A (1992) Sensitivity to sensitins and tuberculin in Swedish children. IV. The influence of BCGvaccination. Eur Respir J 5: 584-586.

34. Bugiani M, Arossa W, Cavellero M, Caria E, Carosso A, et al. (1999) Tuberculin reactivity in BCG-vaccinated subjects. 118-PD. Abstract book 30th IUATLD World Conference on Lung Health. Madrid, Spain.

35. Mudido PM, Guwatudde D, Nakakeeto MK, Bukenya GB, Nsamba D, et al. (1999) The effect of bacille Calmette-Guérin vaccination at birth on tuberculin skin test reactivity in Ugandan children. Int J Tuberc Lung Dis 3: 891-895.

36. Tripathy SP (1994) Fifteen years follow up of the Indian BCG prevention trial. XXVth World Conference of the International Union against $\mathrm{TB}$ Singapore.

37. Bagshawe A, Scott GC, Russell DA, Wigley SC, Merianos A, et al. (1989) BCG vaccination in leprosy: final results of the trial in Karimui, Papua New Guinea, 1963-79. Bull World Health Organ 67: 389-399.

38. Sousa AO, Salem JL, Lee FK, Vercosa MC, Cruaud P, et al. (1997) An epidemic of tuberculosis with a high rate of tuberculin anergy among a population previously unexposed to tuberculosis, the Yanomami Indians of the Brazilian Amazon. Proc Natl Acad Sci U S A 94: 13227-13232.

39. Corrah T, Byass P, Jaffar S, Thomas V, Bouchier V, et al. (2000) Prior BCG vaccination improves survival of Gambian patients treated for pulmonary tuberculosis. Trop Med Int Health 5: 413-417.

40. Baghaie N, Masjedi M, Velayati A (1999) Accuracy of BCG vaccination in prevention of tuberculous meningitis. 413-PD. Absract book 30th IUATLD World Conference on Lung Health. Madrid, Spain.

41. Smith DW, McMurray DN, Wiegeshaus EH, Grover AA, Harding GE (1970) Host-parasite relationships in experimental airborne tuberculosis. IV. Early events in the course of infection in vaccinated and nonvaccinated guinea pigs. Am Rev Respir Dis 102: 937-949. 